Two new coor di nat i on pol ymers, a tri nucl ear met al compl ex and thei $r$ int er conver si on depending on the sol vent

\begin{tabular}{|l|l|}
\hline 著者 & $\begin{array}{l}\text { Koi ke Shi or i, Hi r akawa Takeshi, Yamani shi } \\
\text { Kat sunor i, Kondo M t sur u }\end{array}$ \\
\hline $\begin{array}{l}\text { j our nal or } \\
\text { publ i cat i on ti t l e }\end{array}$ & Dal t on Tr ansact i ons \\
\hline vol une & 43 \\
\hline number & 34 \\
\hline page range & $12832-12835$ \\
\hline year & 2014 07- 14 \\
\hline 出版者 & Royal Soci et y of Chem st ry \\
\hline 権利 & (C) Royal Soci et y of Chemi st ry 2015 \\
\hline URL & ht t p: //hdl . handl e. net /10297/9089 \\
\hline
\end{tabular}




\title{
Two New Coordination Polymers, a Trinuclear Metal Complex and Their Interconversion depending on Solvent
}

\author{
Shiori Koike, ${ }^{a}$ Takeshi Hirakawa, ${ }^{a}$ Katsunori Yamanishi, ${ }^{b}$ and Mitsuru Kondo ${ }^{*, a, c}$ \\ Received (in XXX, XXX) Xth XXXXXXXXX 20XX, Accepted Xth XXXXXXXXX 20XX \\ DOI: $10.1039 /$ b000000x
}

Two new 1-D coordination polymers and a discrete trinuclear complex with a double-ring framework were synthesized and structurally characterized. The unique irreversible conversion from one of the 1-D coordination polymers to the trinuclear 10 complex by contact with MeCN is described.

Selective constructions of multinuclear metal complexes by selfassembly processes are fundamental subjects in supramolecular chemistry. ${ }^{1}$ Bis-imidazole- and bis-benzimidazole-type ligands with two methylene groups $^{2}$ have produced coordination 15 polymers $^{3}$ as well as discrete molecules ${ }^{4,5,6}$ that have $M_{2} L_{4}, M_{2} L_{2}$, and $M_{3} L_{4}$-type cage structures. The metal ions, anions, and solvents used in the syntheses are important factors in the obtained structures. In many cases, the anion is included in the cage of the obtained compounds, because they act as a template ${ }_{20}$ guest to create the cage frameworks. Among the discrete metal complexes, $\mathrm{M}_{3} \mathrm{~L}_{4}$-type complexes are still rare. ${ }^{5}$ This is because it is quite difficult to terminate the multinucleation at the trinuclear structure when the formation of polynuclear structures could be obtainable.

${ }_{25}$ We have focused on the self-assembled system constructed from 1,4-bis(imidazol-1-ylmethyl)-2,3,5,6-tetramethylbenzene (bitb) and $\mathrm{Cu}^{2+}$ ions. ${ }^{6,7}$ When $\mathrm{ClO}_{4}{ }^{-}$or $\mathrm{BF}_{4}{ }^{-}$ions are present, the combination of $\mathrm{Cu}^{2+}$ and bitb yields an $\mathrm{M}_{2} \mathrm{~L}_{4}$-type molecular capsule, which includes the anion in the cage. When $\mathrm{CO}_{3}{ }^{2-}$ is

30 used as the anion of the system, a 2-D coordination polymer is obtained. ${ }^{7}$ Interestingly, this coordination polymer converts to the pentanuclear $\mathrm{Cu}(\mathrm{II})$ complex including the $\left[\mathrm{Cu}\left(\mathrm{CO}_{3}\right)_{2}\right]^{2-}$ anion by treatment with $\mathrm{MeOH}$ or $\mathrm{EtOH}$. This conversion from the 2-D coordination polymer to the pentanuclear metal complexes 35 would be induced by the template anion $\left[\mathrm{Cu}\left(\mathrm{CO}_{3}\right)_{2}\right]^{2-}$.

Structural changes in response to the solvents present have often been observed in some coordination polymers. ${ }^{8,9}$ As a typical example, $\left[\mathrm{Zn}_{2}(\mathrm{oba})_{2}(\mathrm{dmf})_{2}\right]_{n}$ (oba $=1,4$-bisoxybenzoate) with a porous framework reversibly converts to $\left[\mathrm{Zn}(\mathrm{oba})\left(\mathrm{H}_{2} \mathrm{O}\right)\right]_{n}$ 40 without a porous framework, depending on the solvents present, $\mathrm{H}_{2} \mathrm{O}$ or DMF. ${ }^{9}$ However, structural changes from coordination polymers to discrete molecules are still limited. ${ }^{7}$ To explore this conversion reaction, we have continued our synthetic studies of

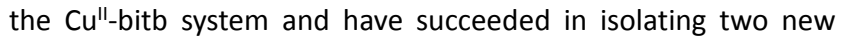

${ }_{45} \mathrm{Cu}$ "-bitb coordination polymers and a new $\mathrm{M}_{3} \mathrm{~L}_{4}$-type trinuclear complex. Their formations are largely dependent on the solvents used in the reactions. This communication reports the syntheses, structures, and a new structural conversion from coordination polymer to trinuclear $M_{3} L_{4}$-type complex responding to the 50 solvent.

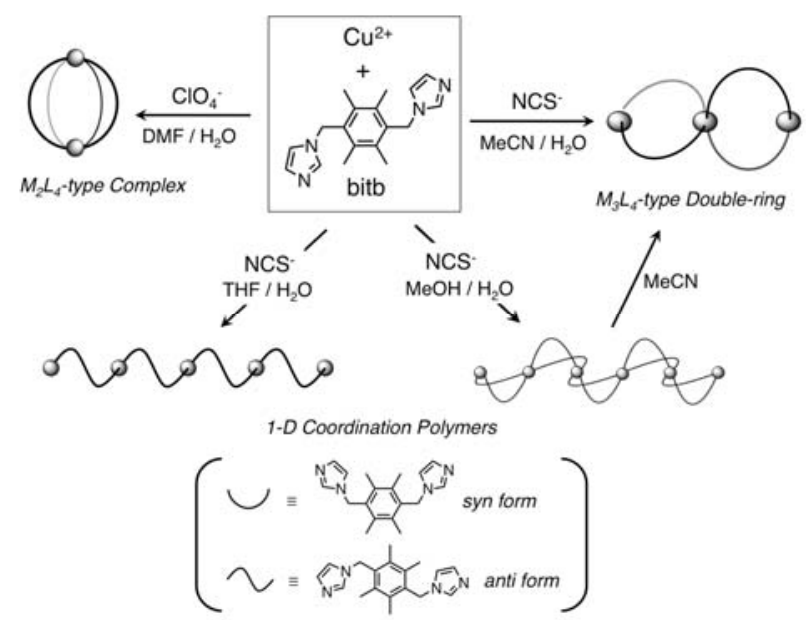

Scheme 1. Schematic images of structural motifs of Cu"-bitb complexes and the irreversible conversion from the coordination polymer to the discrete trinuclear complex observed in this work.

The Cu"-bitb self-assembled system in this work is schematically summarized in Scheme 1. A methanol solution (30 $\left.{ }_{60} \mathrm{ml}\right)$ of bitb $(0.141 \mathrm{~g}, 0.48 \mathrm{mmol})$, a $\mathrm{MeOH}: \mathrm{H}_{2} \mathrm{O}(1: 1 \mathrm{v} / \mathrm{v})$ mixed solution $(30 \mathrm{ml})$ of $\mathrm{NaSCN}(0.039 \mathrm{~g}, 0.48 \mathrm{mmol})$, and an aqueous solution $(30 \mathrm{ml})$ of $\mathrm{CuSO}_{4} \cdot 5 \mathrm{H}_{2} \mathrm{O}(0.060 \mathrm{~g}, 0.24 \mathrm{mmol})$ were mixed. The reaction solution was stirred for a few days to yield $\left\{\left[\mathrm{Cu}(\mathrm{bitb})_{2}(\mathrm{NCS})\right] \mathrm{NCS} \cdot 2 \mathrm{MeOH} \cdot \mathrm{H}_{2} \mathrm{O}\right\}_{n}(\mathbf{1})$ as a blue powder, which ${ }_{65}$ was collected by filtration $(0.097 \mathrm{~g}, 0.11 \mathrm{mmol}, 47.5 \%)$. Calcd for $\mathrm{C}_{40} \mathrm{H}_{54} \mathrm{CuN}_{10} \mathrm{O}_{3} \mathrm{~S}_{2}$ (850.60): C, 56.48; $\mathrm{H}, 6.40 ; \mathrm{N}, 16.47$. Found: $\mathrm{C}$, $56.55 ; \mathrm{H}, 6.22 ; \mathrm{N}, 16.51$. When THF was used instead of $\mathrm{MeOH}$, $\left\{\left[\mathrm{Cu}(\mathrm{bitb})(\mathrm{NCS})_{2}\left(\mathrm{H}_{2} \mathrm{O}\right)\right] \mathrm{THF}\right\}_{n}$ (2) was obtained as a deep green powder in $64.3 \%$ yield. Calcd for $\mathrm{C}_{24} \mathrm{H}_{32} \mathrm{CuN}_{6} \mathrm{O}_{2} \mathrm{~S}_{2}$ (564.22): $\mathrm{C}$, 70 51.09; $\mathrm{H}, 5.72 ; \mathrm{N}, 14.89$. Found: $\mathrm{C}, 51.30 ; \mathrm{H}, 5.74 ; \mathrm{N}, 14.41$. On the other hand, similar treatment of $\mathrm{CuCl}_{2} \cdot 2 \mathrm{H}_{2} \mathrm{O}$ with bitb and $\mathrm{NaSCN}$ in $\mathrm{MeCN} / \mathrm{H}_{2} \mathrm{O}$ media produced $\left[\mathrm{Cu}_{3}(\mathrm{bitb})_{4}(\mathrm{NCS})_{6}\right](3)$ as a green powder in $61.4 \%$ yield. Calcd for $\mathrm{C}_{78} \mathrm{H}_{88} \mathrm{Cu}_{3} \mathrm{~N}_{22} \mathrm{~S}_{6}$ (1716.70): C, 54.57; H, 5.17; N, 17.95. Found: C, 54.58; H, 5.18; N, 18.01. 75 The single crystals of each compound for $\mathrm{X}$-ray diffraction studies were obtained by the diffusion method at about $33 \%, 41 \%$, and $50 \%$ yield respectively. 
The structures of $\mathbf{1}, \mathbf{2}$, and $\mathbf{3}$ were clarified by single-crystal $X$ ray diffraction studies. Figure 1 shows the coordination environment of the $\mathrm{Cu}^{\prime \prime}$ center and the infinite network structures of $\mathbf{1}$. The $\mathrm{Cu}^{\text {ll }}$ center is based on a square pyramid with 5 four imidazole nitrogen atoms of bitb, and an $\mathrm{NCS}^{-}$nitrogen atom at the apical site (Figure 1a). The $\mathrm{Cu}-\mathrm{N}$ bond distance (2.182(6) $\AA$ ) formed between the $\mathrm{Cu}^{\prime \prime}$ center and the NCS nitrogen is slightly longer than those of the other $\mathrm{Cu}-\mathrm{N}$ bonds (avg. $2.009 \AA$ ) formed between the $\mathrm{Cu}^{\prime \prime}$ center and the imidazole 10 nitrogen atoms. As shown in Figure $1 \mathrm{~b}$, each $\mathrm{Cu}^{\text {ll }}$ center is connected by two bitb in the syn form to yield a 1-D structure along the $b$-axis. The imidazole nitrogen atoms of the two bitb ligands that bridge the pair of $\mathrm{Cu}^{\prime \prime}$ ions occupy the cis-positions at the $\mathrm{Cu}^{\prime \prime}$ center. As a result, a unique zigzag chain motif is 15 constructed.

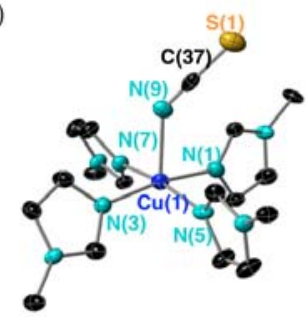

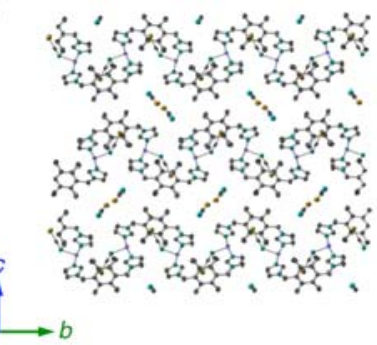

b)

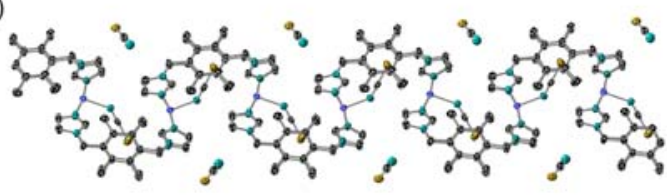

Figure 1. Thermal ellipsoids of the coordination environment around the $\mathrm{Cu}^{\prime \prime}$ center of $\mathbf{1}$ (a). The 1-D structure along the $b$-axis 20 (b) and the overall structure (c) of $\mathbf{1}$. Hydrogen atoms, and water and $\mathrm{MeOH}$ molecules included in the channels are omitted for clarity.

The $\mathrm{NCS}^{-}$binds to the $\mathrm{Cu}^{\prime \prime}$ center with remarkably bent $\mathrm{Cu}-\mathrm{N}-$ ${ }_{25} \mathrm{C}$ bond angles $\left(139.7(6)^{\circ}\right)$. Although the sulfur atom of the NCS orients to the vacant site of the $\mathrm{Cu}^{\prime \prime}$ ion in the same chain, the longer $\mathrm{Cu}---\mathrm{S}$ distance ( $c a .3 .9 \AA$ ) indicates that there is no significant interactions between the $\mathrm{Cu}^{\prime \prime}$ center and the sulfur atom. As shown in Figure 1C, the 1-D chains assemble to create 301 -D channels along the $a$-axis with a size of about $1.5 \times 1.5 \AA^{2}$. While 1 involves two $\mathrm{NCS}^{-}$ions per $\mathrm{Cu}^{\prime \prime}$ ion, one does not bind to the $\mathrm{Cu}^{\prime \prime}$ center. The channels are occupied with the metal-free $\mathrm{NCS}^{-}$ions, water and methanol molecules.

Figure 2 shows the coordination environment and network 35 structure of $\mathbf{2}$. The $\mathrm{Cu}^{\text {Il }}$ center is based on a square pyramid with two imidazole nitrogen atoms of bitb, two $\mathrm{NCS}^{-}$nitrogen atoms, and a water oxygen atom at the apical position. The $\mathrm{Cu}-\mathrm{O}$ bond distance $(2.687(14) \AA)$ is significantly longer than the $\mathrm{Cu}-\mathrm{N}$ bond distances $(1.92 \sim 2.03 \AA$ ) because of the Jahn-Teller effect. As 40 shown in this figure, the $\mathrm{Cu}-\mathrm{O}$ unit is disordered at the two positions by the crystallographic inversion center located between the two $\mathrm{Cu}^{\prime \prime}$ centers. The $\mathrm{Cu}$ atom is pulled about $0.2 \AA$ from the plane defined by the four coordinating nitrogen atoms toward the water oxygen atom. The $\mathrm{Cu}-\mathrm{N}$ bond distances

45 between the $\mathrm{Cu}^{\prime \prime}$ ion and the imidazole nitrogen atoms (avg. $2.012 \AA$ ) are slightly longer than those between the $\mathrm{Cu}^{\text {Il }}$ and NCS ions (avg. $1.952 \AA$ A ). Two $\mathrm{NCS}^{-}$ions bind to the $\mathrm{Cu}^{\prime \prime}$ center with nearly linear $\mathrm{Cu}-\mathrm{N}-\mathrm{C}$ bond angles (avg. $172.8^{\circ}$ ).

Each Cull center is connected by bitb in the anti form to yield 50 zigzag 1-D chains along the $(a+b)$ vector (Figure $2 \mathrm{~b})$. Compound 2 contains a THF molecule per $\mathrm{Cu}^{\prime \prime}$ atom. The THF molecule, which is disordered at the two positions, forms a hydrogen bond with the coordinating water molecule $(\mathrm{O} \cdots \mathrm{O}=$ avg. $2.988 \AA$ ) .

a)

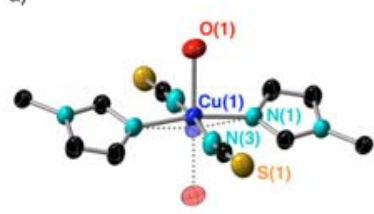

c)
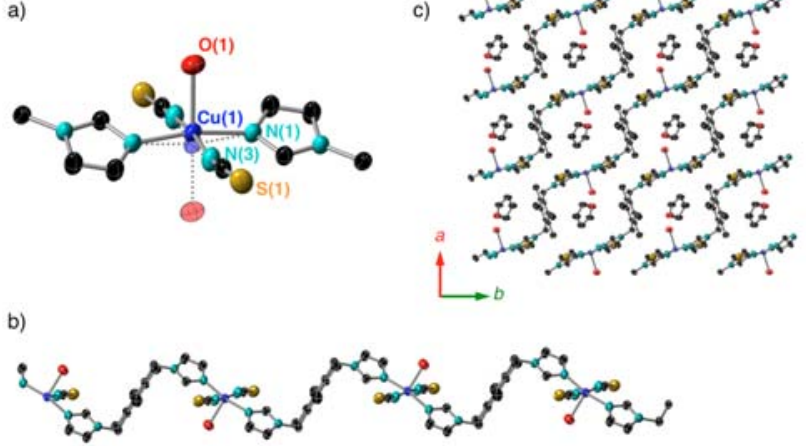

Figure 2. Thermal ellipsoids of coordination environment around the $\mathrm{Cu}^{\prime \prime}$ center of $\mathbf{2}$ (a). The disordered $\mathrm{Cu}(1)$ and $\mathrm{O}(1)$ atoms are shown by the transparent ellipsoids. The 1-D structure along the $(a+b)$ vector (b). Hydrogen atoms are omitted for clarity. ${ }_{60}$ Disorders are also omitted in (b) and (c) for clarity.

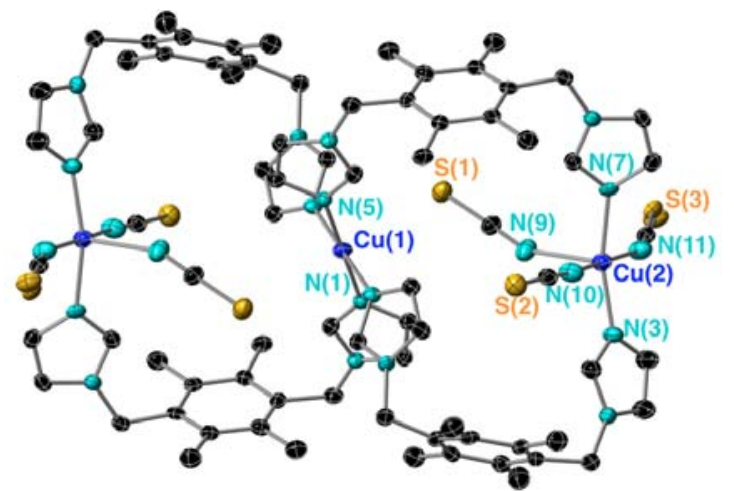

Figure 3. Thermal ellipsoids of molecular structure of $\mathbf{3}$. ${ }_{65}$ Hydrogen atoms are omitted for clarity.

In contrast to $\mathbf{1}$ and 2, $\mathbf{3}$ has a discrete trinuclear structure with double-ring framework, which is also called a twin-cage framework. As shown in Figure 3, this framework is constructed 70 by connections of three $\mathrm{Cu}^{\prime \prime}$ ions by four bitb ligands to give double rings connected at the $\mathrm{Cu}(1)$ atom. The crystallographic inversion center is located at the $\mathrm{Cu}(1)$ atom. For the three $\mathrm{Cu}^{\prime \prime}$ centers, $\mathrm{Cu}(2)$ atoms located in both edges of the double-ring framework are based on the square pyramidal coordination 75 environment with two imidazole nitrogen atoms and three NCS nitrogen atoms. For the three crystallographically independent $\mathrm{NCS}^{-}$ligands in 3, $\mathrm{N}(10)-\mathrm{C}(38)-\mathrm{S}(2)^{-}$binds with the $\mathrm{Cu}^{\prime \prime}$ ion with a nearly linear $\mathrm{Cu}-\mathrm{N}-\mathrm{C}$ bond angle $\left(171.0(5)^{\circ}\right)$, while the other two $\mathrm{NCS}^{-}$ligands show remarkably bent $\mathrm{Cu}-\mathrm{N}-\mathrm{C}$ bond angles ${ }_{80}\left(149.9(5)^{\circ}\right.$ and $\left.154.7(5)^{\circ}\right)$. Of the five $\mathrm{Cu}-\mathrm{N}$ bonds, the $\mathrm{Cu}(1)-\mathrm{N}(9)$ 
bond $(2.275(6) \AA)$ is longer than the others (avg. $1.991 \AA$ ) because of the Jahn-Teller effect. The sulfur atom of one of the NCS $^{-}$ligands orients to the axial site of the $\mathrm{Cu}(1)$ atom. The $\mathrm{Cu}(1) \cdots \mathrm{S}(1)$ distance (ca. $3.1 \AA$ ) is shorter than the sum of the van 5 der Waals radii of copper $(1.4 \AA)$ and sulfur $(1.85 \AA)$ atoms, indicating an association of the $\mathrm{S}(1)$ atom to the $\mathrm{Cu}(1)$ atom. As a result, the $\mathrm{Cu}(1)$ atom is based on the elongated octahedral geometry with four imidazole nitrogen atoms and the sulfur atoms.

10 Compounds $\mathbf{1}, \mathbf{2}$, and $\mathbf{3}$ were obtained depending on the organic solvents included in the reaction solutions when they were prepared. We studied whether or not these three organic solvents induce structural conversions among $\mathbf{1}, \mathbf{2}$, and $\mathbf{3}$. Because these three compounds were only sparsely soluble in 15 their solvents, $\mathrm{MeOH}, \mathrm{THF}$, and $\mathrm{MeCN}$, the structural changes were monitored by measurements of $\mathrm{X}$-ray powder diffraction (XRPD) patterns of each bulk sample before and after stirring in the solvents for a week. We found that $\mathbf{1}$ is converted to $\mathbf{3}$ irreversibly in this condition. Figure 4 shows the XRPD charts of a 20 fresh sample of $\mathbf{1}$, the powder sample obtained after stirring of $\mathbf{1}$ in MeCN for a week, and simulated XRPD patterns of $\mathbf{1}$ and $\mathbf{3}$, which were obtained based on their crystal structures.

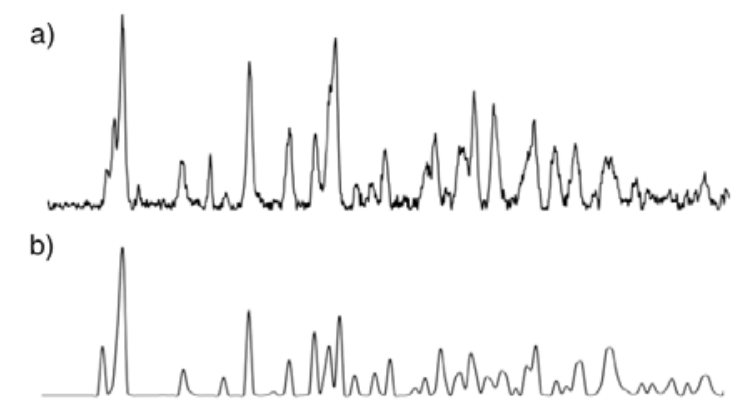

c)

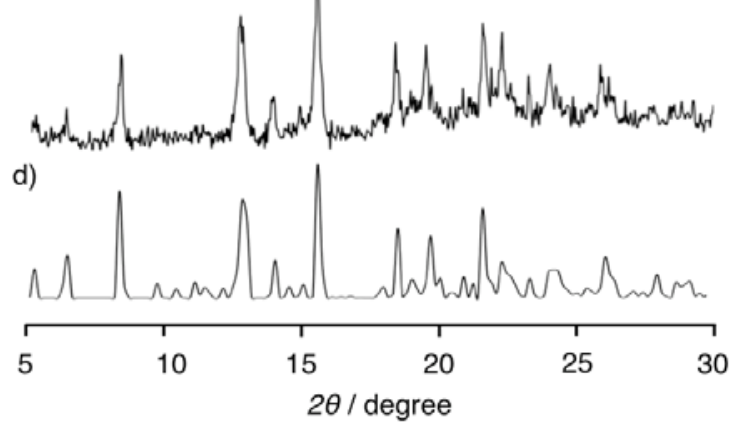

${ }_{25}$ Figure 4. XRPD ( $\left.\mathrm{Cu} \mathrm{K} \alpha\right)$ pattern of a fresh sample of $\mathbf{1}(\mathrm{a})$ and the powder sample obtained after stirring 1 in MeCN for a week (c) with the simulated XRPD pattern for $\mathbf{1}(b)$ and $\mathbf{3}(\mathrm{d})$.

The XRPD peaks characteristic for 1 disappeared on treatment 30 with $\mathrm{MeCN}$, and the XRPD peaks of a pattern similar to the simulated pattern of $\mathbf{3}$ appeared. This result indicates that $\mathbf{1}$ converts to 3 by treatment with MeCN. We also studied whether or not the reverse conversion, i.e., from $\mathbf{3}$ to $\mathbf{1}$, was induced by contact with $\mathrm{MeOH}$. The XRPD pattern of the bulk sample of $\mathbf{3}$

35 was not changed essentially after stirring the bulk sample in $\mathrm{MeOH}$ for 2 weeks (Figure S12 in Supplementary Information), indicating that conversion from $\mathbf{3}$ to $\mathbf{1}$ did not occur on treatment with $\mathrm{MeOH}$ in this condition. This result reveals that $\mathbf{1}$ converts to $\mathbf{3}$ irreversibly.

40 The conversion from $\mathbf{1}$ to $\mathbf{3}$ was also confirmed by measurement of reflectance spectra. Compounds $\mathbf{1}$ and $\mathbf{3}$ show $\mathrm{d}-\mathrm{d}$ absorption at $\lambda_{\max }=673$ and $696 \mathrm{~nm}$ in the reflectance spectra (Figure S18 and S20). The spectrum of the powder sample obtained by contact of 1 with MeCN for a week was quite 45 similar to that of 3 (Figure S21), although the change of the color was not clear in visible. For the conversion reaction, the XRPD peaks of 1 disappeared within 4 days because of the formation of amorphous state, and then new peaks ascribed to 3 appeared within additional three days (Figure S11). For 50 construction of the double-ring framework of $\mathbf{3}$ from 1, clevages of $\mathrm{Cu}-\mathrm{N}$ (imidazole) bonds and formations of new $\mathrm{Cu}-\mathrm{N}$ (imidazole) and $\mathrm{Cu}-\mathrm{N}$ ( $\mathrm{NCS}^{-}$anions) bonds are involved. The dynamic rearrangements which yield double-ring frameworks selectively would be difficult in the solid state. Despite $\mathbf{1}$ is ${ }_{55}$ sparsely soluble in $\mathrm{MeCN}$ (one piece of crystal is not soluble in $100 \mathrm{~mL}$ of $\mathrm{MeCN}$ ) and other general organic solvents, the conversion from $\mathbf{1}$ to $\mathbf{3}$ could proceed by recrystallization process.

Although we also studied structural conversions between 1 and $\mathbf{2}$ by contact with THF and $\mathrm{MeOH}$, and between $\mathbf{2}$ and $\mathbf{3}$ by 60 contact with MeCN and THF, these combinations did not induce structural changes under the above conditions. Their XRPD charts are shown in the Supplementary Information (Figure S9, S10, S13, S14).

In conclusion, treatments of $\mathrm{CuSO}_{4} \cdot 5 \mathrm{H}_{2} \mathrm{O}$ or $\mathrm{CuCl}_{2} \cdot 2 \mathrm{H}_{2} \mathrm{O}$, bitb, ${ }_{65}$ and $\mathrm{NaSCN}$ yielded two new coordination polymers and a new discrete trinuclear complex with an $\mathrm{M}_{3} \mathrm{~L}_{4}$-type double-ring structure. Their formations are dependent on the kinds of organic solvents included in the reaction solvents. To clarify the effects of the organic solvents on the obtained structures, we 70 studied the structural changes among the three compounds by contact with the organic solvents, $\mathrm{MeOH}, \mathrm{THF}$, and $\mathrm{MeCN}$. This study showed that $\mathbf{1}$ converts to $\mathbf{3}$ irreversibly by contact with $\mathrm{MeCN}$, while no other conversions were observed after treatment of the bulk samples in the solvents.

75 We thank Y. Yamamoto of Research Institute of Green Science Technology in Shizuoka University for support in obtaining the elemental analysis data. This work was supported by a Grant-inAid for Challenging Exploratory Research (Grant 24655047) from the Japan Society for the Promotion of Science, Japan.

\section{${ }_{80}$ Notes and references}

${ }^{a}$ Department of Chemistry, Faculty of Science, Shizuoka University, 836 Ohya, Suruga-ku, Shizuoka, 422-8529 Japan

${ }^{b}$ Graduate School of Science and Technology, Shizuoka University, 836 Ohya, Suruga-ku, Shizuoka 422-8529 Japan.

$85^{c}$ Green Chemistry Research Division, Research Institute of Green Science Technology, Shizuoka University, 836 Ohya, Suruga-ku, Shizuoka 422-8529, Japan.scmkond@ipc.shizuoka.ac.jp

+ Electronic supplementary information (ESI) available: Materials and methods, crystallographic data, XRD charts, UV-vis. reflectance spectra, 90 IR spectra. CCDC 990125 (1), 990127 (2), 990126 (3). For ESI and crystallographic data in CIF or other electronic format see DOI:

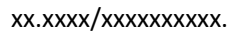

¥ Footnotes should appear here. These might include comments relevant to but not central to the matter under discussion, limited 95 experimental and spectral data, and crystallographic data. 
1. (a) J.-M. Lehn, Supramolecular chemistry, VCH, Weinheim, 1995. (b) G. F. Swiegers and T. J. Malefetse, Chem. Rev., 2000, 100, 3483-3537. (c) T. R. Cook, Y.-R. Zheng and P. J. Stang, Chem. Rev., 2013, 113, 734777.

5 2. (a)C.-L. Chen, J.-Y. Zhang and C.-Y. Su, Eur. J. Inorg. Chem., 2007, 2997-3010. (b) G.-H. Cui, J.-R. Li, J.-L. Tian, X.-H. Bu and S. R. Batten, Cryst. Growth. Des., 2005, 5, 1775-1780. (c) Y. Qi, F. Luo, S. R. Batten, Y.-X. Che and J.-M. Zheng, Cryst. Growth. Des., 2008, 8, 2806-2813. (d) J. Fan, W.-Y. Sun, T.-a. Okamura, Y.-Q. Zheng, B. Sui, W.-W. Tang and N. Ueyama, Cryst. Growth. Des., 2004, 4, 579-584.

3. (a) J. Yang, J.-F. Ma, Y.-Y. Liu, J.-C. Ma and S. R. Batten, Cryst. Growth. Des., 2008, 8, 4383-4393. (b) H.-K. Liu, J. Hu, T.-W. Wang, X.-L. Yu, J. Liu and B. Kang, J. Chem. Soc., Dalton Trans., 2001, 3534-3540. (c) C.Y. Su, Y.-P. Cai, C.-L. Chen and B.-S. Kang, Inorg. Chem., 2001, 40, 2210-2211. (d) H. Amouri, C. Desmarets, A. Bettoschi, M. N. Rager, K. Boubekeur, P. Rabu and M. Drillon, Chem. Eur. J., 2007, 13, 54015407.

4. (a) C.-Y. Su, Y.-P. Cai, C.-L. Chen, H.-X. Zhang and B.-S. Kang, J. Chem. Soc., Dalton Trans., 2001, 359-361. (b) C.-Y. Su, Y.-P. Cai, C.-L. Chen, M.

20 D. Smith, W. Kaim and H.-C. zur Loye, J. Am. Chem. Soc., 2003, 125, 8595-8613. (c) N. Kishi, Z. Li, K. Yoza, M. Akita and M. Yoshizawa, J. Am. Chem. Soc., 2011, 133, 11438-11441.

5. H.-K. Liu, C.-Y. Su, C.-M. Qian, J. Liu, H.-Y. Tan and B.-S. Kang, J. Chem. Soc., Dalton Trans., 2001, 1167-1168.

256 . (a) T. Hirakawa, M. Yamaguchi, N. Ito, M. Miyazawa, N. Nishina, M. Kondo, R. Ikeya, S. Yasue, K. Maeda and F. Uchida, Chem. Lett., 2009, 38, 290-291. (b) M. Yamaguchi, T. Hirakawa, N. Nishina, M. Kondo, H. Aoki, E. Okuda and L. Zhang, Chem. Lett., 2010, 39, 1192-1193.

7. T. Inoue, K. Yamanishi and M. Kondo, Inorg. Chem., 2013, 52, 47654767.

8. (a) J. J. Vittal and G. K. Kole, Chem. Soc. Rev., 2013, 42, 1755-1775. (b) E. V. Dikarev, B. Li, V. V. Chernyshev, R. V. Shpanchenkob and M. A. Petrukhina, Chem. Commun., 2005, 3274-3276. (c) J.-P. Zhang, X.-C. Huang and X.-M. Chen, Chem. Soc. Rev., 2009, 38, 2385-2396. (d) K. Fujii, Y. Ashida, H. Uekusa, S. Hirano, S. Toyota, F. Toda, Z. Pan and K. D. M. Harris, Cryst. Growth. Des., 2009, 9, 1201-1207. (e) H.-Q. Hao, W.-T. Liu, W. Tan, Z. Lin and M.-L. Tong, Cryst. Growth. Des., 2009, 9 457-465. (f) A. M. P. Peedikakkal and J. J. Vittal, Cryst. Growth. Des., 2011, 11, 4697-4703. (g) A. M. Plonka, D. Banerjee and J. B. Parise, $40 \quad$ Cryst. Growth. Des., 2012, 12, 2460-2467. (h) R. Saha, S. K. Dey, S. Biswas, A. D. Jana and D. Kumar, Cryst. Growth. Des., 2013, 13, 21352142.

9. M. Kondo, Y. Irie, Y. Shimizu, M. Miyazawa, H. Kawaguchi, A. Nakamura, T. Naito, K. Maeda and F. Uchida, Inorg. Chem., 2004, 43 6139-6141. 